\title{
The Very High Cycle Fatigue Behaviour of Ti-6Al-4V Alloy
}

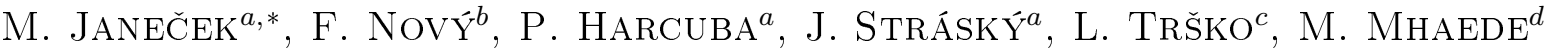 \\ AND L. WAGNER ${ }^{d}$ \\ ${ }^{a}$ Charles University in Prague, Department of Physics of Materials, \\ Ke Karlovu 5, CZ-12116, Prague, Czech Republic \\ ${ }^{b}$ University of Žilina, Department of Materials Engineering, Žilina, Slovak Republic \\ ${ }^{c}$ Research Center of the University of Žilina, Žilina, Slovak Republic \\ ${ }^{d}$ Clausthal University of Technology, Institute of Materials Science and Technology, Clausthal-Zellerfeld, Germany

\begin{abstract}
The high cycle and very high cycle fatigue properties of the titanium alloy $\mathrm{Ti}-6 \mathrm{Al}-4 \mathrm{~V}$ with a duplex microstructure were investigated at room temperature. High cycle fatigue tests were performed in the range from $10^{4}$ to $10^{7}$ cycles by rotating bending at the frequency of $30 \mathrm{~Hz}$. The very high cycle fatigue tests were carried out in of $20 \mathrm{kHz}$. The stress amplitude was found to decrease with increasing number of cycles in the whole range from $10^{4}$ up to $10^{9}$ cycles and only at the highest number of cycles $\left(N_{\mathrm{F}}=10^{9}\right)$ the alloy exhibits the fatigue limit of $460 \mathrm{MPa}$. The detail fractographic analysis was performed to characterize the fatigue failure mechanisms. Both subsurface and surface crack initiation were observed in very high cycle fatigue region. No inclusions, but only local chemical inhomogeneity in microstructure was observed at the locations of subsurface fatigue crack initiation in alpha-grains.
\end{abstract} \\ the range from $10^{7}$ to $10^{10}$ cycles in tension-compression on an ultrasonic fatigue testing machine at the frequency
}

DOI: $10.12693 /$ APhysPolA.128.497

PACS: 46.50.+a, 62.20.M-, 81.40.Np

\section{Introduction}

Titanium alloys used as biomaterials for permanent orthopaedic implants are predominantly subjected to cyclic loading. They are required to safe operation over long periods of life, extending much beyond billion cycles. Among various materials currently employed, the alloy $\mathrm{Ti}-6 \mathrm{Al}-4 \mathrm{~V}$ has found extensive biomedical applications due to its good mechanical properties and ability for osseointegration, combined with an excellent corrosion behavior due to passivity [1].

Good fatigue performance is the most important factor for cyclically loaded components to ensure long-term reliability. The classical description of metal fatigue was developed during the 19th century and since that time the main aspects of the lifetime-oriented fatigue behavior of metals have been generally represented in the form of $\mathrm{S}-\mathrm{N}$ curves. In conventional fatigue design, the fatigue limit is usually determined by the fatigue strength at specified number of cycles [2]. Based on the fatigue life concept, the metal fatigue can be subdivided into three categories. The first one is the low cycle fatigue (LCF) - up to $10^{5}$ cycles to failure, the second one is the high cycle fatigue (HCF) - between $10^{5}$ and $10^{8}$ cycles to failure and the third one is the very high cycle fatigue (VHCF) - over $10^{8}$ cycles to failure [3]. However, measurement of VHCF using common devices is extremely time-consuming and therefore often not executed.

* corresponding author; e-mail: janecek@met.mff.cuni.cz
During the last decade it was indicated that the common comprehension of $\mathrm{S}-\mathrm{N}$ curves has to be revised in the very high cycle fatigue $[4,5]$. Numerous data exist for spring and bearing steels in the VHCF region $[6,7]$. On the other hand, investigation of VHCF behaviour of light metals, as e.g. magnesium and titanium and their alloys is reported in the literature relatively sparsely $[8,9]$ or in a general manner only [10].

The objective of this investigation is to characterize the VHCF fatigue behavior of Ti- $6 \mathrm{Al}-4 \mathrm{~V}$ alloy and to compare it with processes occurring during HCF fatigue.

\section{Experimental procedure}

The Ti-6Al-4V alloy was used in this investigation. The chemical composition is declared by the supplier: $\mathrm{Al}$ (5.5-6.75 wt.\%), V (3.5-4.5 wt.\%), O $(<0.2 \%)$, $\mathrm{Fe}(<0.3$ wt.\%) and $\mathrm{C}(<0.1 \%), \mathrm{H}(<0.015 \mathrm{wt} . \%)$ and $\mathrm{N}(<0.05 \mathrm{wt} . \%)$. The beta transus of the alloy is $995^{\circ} \mathrm{C}$.

The material was prepared by annealing at $980^{\circ} \mathrm{C}$ for $1 \mathrm{~h}$ followed by water quenching. Subsequently it was annealed at $800^{\circ} \mathrm{C}$ for $1 \mathrm{~h}$ followed by air cooling. Final aging was performed at $500^{\circ} \mathrm{C}$ for $24 \mathrm{~h}$ [11].

As the fatigue endurance was determined in a very wide range of cycles $\left(10^{4}-10^{10}\right)$ two different experimental testing machines were employed. The HCF fatigue tests were performed in the range from $10^{4}$ to $10^{7}$ cycles by rotating bending at the testing frequency of $30 \mathrm{~Hz}$. The VHCF tests were carried out under fully reversed loading condition (tension-compression loading, stress ratio $R=-1$ ) on an ultrasonic fatigue testing machine with a piezoactuator operating at the ultrasonic frequency of $20 \mathrm{kHz}$. The detail description of the device can be 
found elsewhere [12]. VHCF tests may be certainly performed also on conventional fatigue machines. However, the duration of these tests would be very long and the determination of a single $\mathrm{S}-\mathrm{N}$ curve would last several years. On the other hand, the employment of high frequency fatigue machines allows running the tests up to $10^{10}$ cycles in approximately one week. Due to technical reasons these machines are not suitable for tests at the HCF region, in particular in the region of LCF $\left(N<10^{5}\right)$ they cannot be used at all. Therefore, conventional testing machine was used in the HCF range.

Fatigue hourglass-shaped specimens of the diameter of $4 \mathrm{~mm}$ were electropolished in their gage section to eliminate potential machining effects. The effect of surface finishing techniques on the fatigue strength of $\alpha$ and $\alpha+\beta$ titanium alloys can be found in [13]. Rotating bending fatigue tests were conducted at the ambient temperature of $\approx 22{ }^{\circ} \mathrm{C}$, and the relative humidity of $\approx 45 \%$. During the high frequency fatigue tests the specimens were cooled by compressive air. The criterion for fatigue life was the final fracture. The complete $\mathrm{S}-\mathrm{N}$ (Wöhler) curve was determined.

The fatigue failure mechanisms were investigated by detailed inspection of fracture surfaces using the scanning electron microscope FEI Quanta 200F equipped with FEG cathode at the accelerating voltage of $20 \mathrm{kV}$. Chemical analysis of the microstructural heterogeneities at the fracture surface was performed by energy dispersive X-ray analyzer EDAX.

\section{Results and discussion}

The typical initial microstructure of the material is shown in the optical micrograph in Fig. 1. The so-called duplex or bi-modal microstructure, with ultimate tensile strength of $1050 \mathrm{MPa}$, and yield strength of $950 \mathrm{MPa}$, consists of $\approx 30$ vol. $\%$ of primary $\alpha$ phase with a size of about $20 \mu \mathrm{m}$ and $\approx 70 \mathrm{vol} . \%$ lamellar colonies of $\alpha+\beta$. It was reported by many authors that the bimodal structure generally ensures good fatigue endurance of the $\mathrm{Ti}-6 \mathrm{Al}-4 \mathrm{~V}$ alloy [14]. The mechanical response of $\mathrm{Ti}-$ $6 \mathrm{Al}-4 \mathrm{~V}$ alloy is, however, extremely sensitive to prior thermo-mechanical processing history, e.g., prior $\beta$ grain size, the ratio of primary $\alpha$ to transformed $\beta$, the $\alpha$ grain size and the $\alpha / \beta$ morphologies, all impacting performance, particularly HCF lifetime. For example, maximum fracture toughness and fatigue crack growth resistance is achieved with the Widmanstätten microstructures resulting from a $\beta$ recrystallization annealing. However, this microstructure results in inferior $\mathrm{HCF}$ performance. Therefore the development of a bi-modal primary $\alpha$ plus transformed $\beta$ microstructure is preferred to prevent fatigue crack initiation. Indeed, the transition to fine equiaxed, fine lamellar, coarse equiaxed and coarse lamellar leads to progressive reductions in fatigue lifetime [15].

Results of fatigue tests are shown in Fig. 2. Fatigue curve (also referred to as Wöhler or $\mathrm{S}-\mathrm{N}$ curve) which

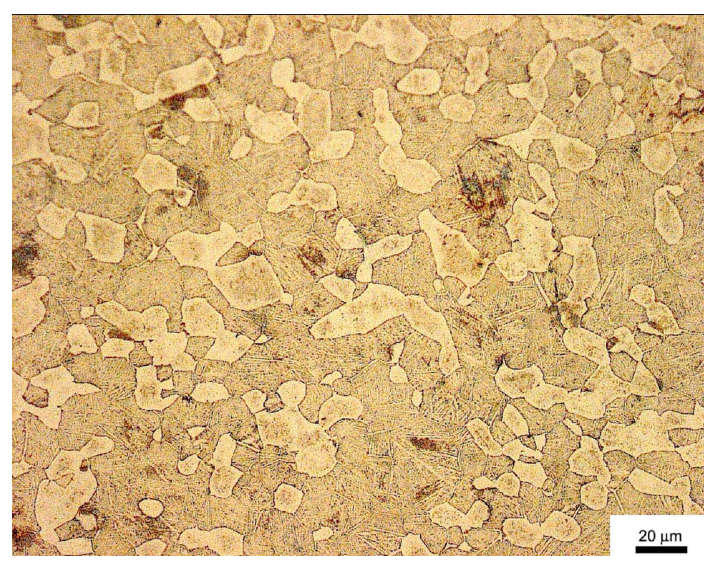

Fig. 1. Duplex (bi-modal structure) - light primary $\alpha$ phase grains and dark lamellar $\alpha+\beta$ colonies (etched in the Kroll solution).

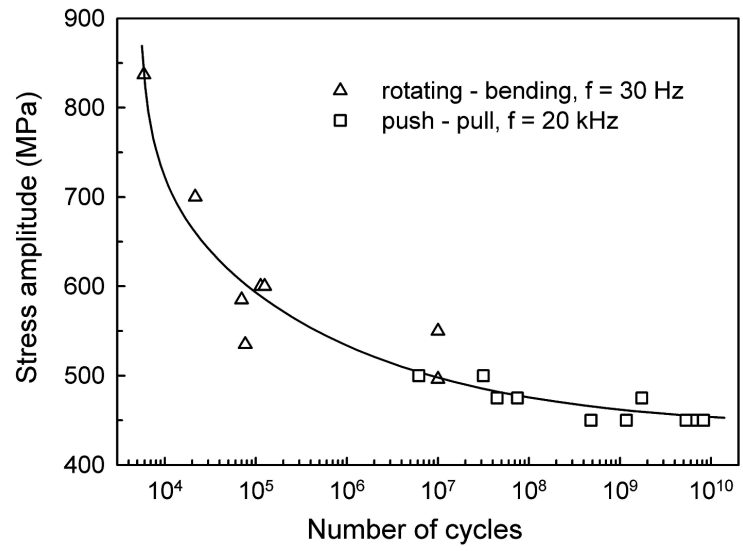

Fig. 2. $\mathrm{S}-\mathrm{N}$ curve of $\mathrm{Ti}-6 \mathrm{Al}-4 \mathrm{~V}$ alloy.

represents the dependence of fatigue life on the number of cycles to failure is usually plotted in the form $\sigma=f(\log N)$ and mathematically described by a Basquin function

$$
\sigma(N)=a N^{b},
$$

where $\sigma$ is stress amplitude, $a$ is parameter of the Basquin function (extrapolated value of function or of the tangent in the point of inflexion for $N=1$ ), $N$ is number of cycles and $b$ is parameter of the Basquin function (in $\log -\log$ fit the slope of oblique asymptote or of the tangent in the point of inflexion).

The validity of the simple Basquin function describing the dependence of fatigue limit of finite life $\sigma(N)$ on the number of cycles $N$ can be extended using the Stromeyer function to the low-cycle region

$$
\sigma(N)=a(N+B)^{b},
$$

as well as to the high-cycle region

$$
\sigma(N)=a N^{b}+\sigma_{\infty},
$$

(where $\sigma_{\infty}$ is permanent fatigue limit) and using the Palmgren function to both the low- and the high-cycle regions 


$$
\sigma(N)=a(N+B)^{b}+\sigma_{\infty} .
$$

Many other functions describing the $\mathrm{S}-\mathrm{N}$ dependence can be also used $[16,17]$, but their application depends on many factors. The Palmgren function (4) was found to be most proper for the description of experimental results in this case. Obtained experimental results of fatigue tests were approximated by the following equation:

$$
\sigma(N)=\left[1700(N-4900)^{-0.2}+440\right] \mathrm{MPa} .
$$

As seen from Fig. 2 fatigue properties characterized by the $\mathrm{S}-\mathrm{N}$ curve obtained under rotating bending $(f=$ $30 \mathrm{~Hz}$ ) and symmetrical tension-compression cyclic loading $(f=20 \mathrm{kHz})$ exhibit a continuous decrease of the stress amplitude with increasing number of cycles in the region from $10^{4}$ to $10^{9}$ cycles. Smooth character of S$\mathrm{N}$ curve indicates the negligible influence of the type of loading. It is well known, however, that the differences between fatigue results obtained using rotating bending and tension-compression loading can be in some cases very significant (up to 20\%) [18]. There are two main parameters controlling the fatigue process, i.e. the amplitude and the rate of microplastic deformation. Due to microplastic deformation heat is generated in specimens during cyclic loading. In order to reduce the heat generation the fatigue tests at higher amplitudes of loading in the range from $10^{4}$ to $10^{7}$ cycles were performed at low frequency of $30 \mathrm{~Hz}$. Above $10^{7}$ cycles the amplitude of microplastic deformation is very low and much less heat is generated in tested specimens. Under these conditions the fatigue tests were performed at higher frequencies $(\approx 20 \mathrm{kHz})$ and very high number of loading cycles $\left(\geq 10^{9}\right)$ was achieved with negligible influence of testing frequency on $\mathrm{S}-\mathrm{N}$ curve.

For higher number of cycles $\left(N>10^{9}\right)$ the stress amplitude remains constant up to $10^{10}$. The VHCF region of Ti-6Al-4V alloy is therefore characterized by an extremely low decrease of fatigue strength $[19,20]$ as compared to most other structural materials, as e.g. structural steels, high strength steels or ADI alloys [7]. From the practical viewpoint $N \approx 10^{8}$ may be set as the fatigue limit of this alloy. On the other hand, the behaviour of the alloy may differ as a result of different heat treatment. A marked decrease in fatigue strength of titanium alloys above $10^{7}$ cycles was observed in [21].

As reported by many authors, also for titanium alloys, there is a common belief that a transition of fatigue crack initiation from the surface to the interior occurs at the low stress amplitudes in VHCF region. The sole surface fatigue crack initiation in the VHCF region was reported only rarely $[19,22]$. However, our detailed fractographic SEM analysis and comparison of fatigue fracture surfaces of Ti-6Al-4V alloy in HCF and in VHCF region revealed only small differences at fracture surfaces corresponding to different stress amplitudes. In most specimens only surface crack initiation was observed, see Fig. 3. Only exceptionally (2 specimens of 10 ) subsurface initiation with a star- or a rosette-like character occurred, see Fig. 4. Contrary to other authors [10] our observations indicate

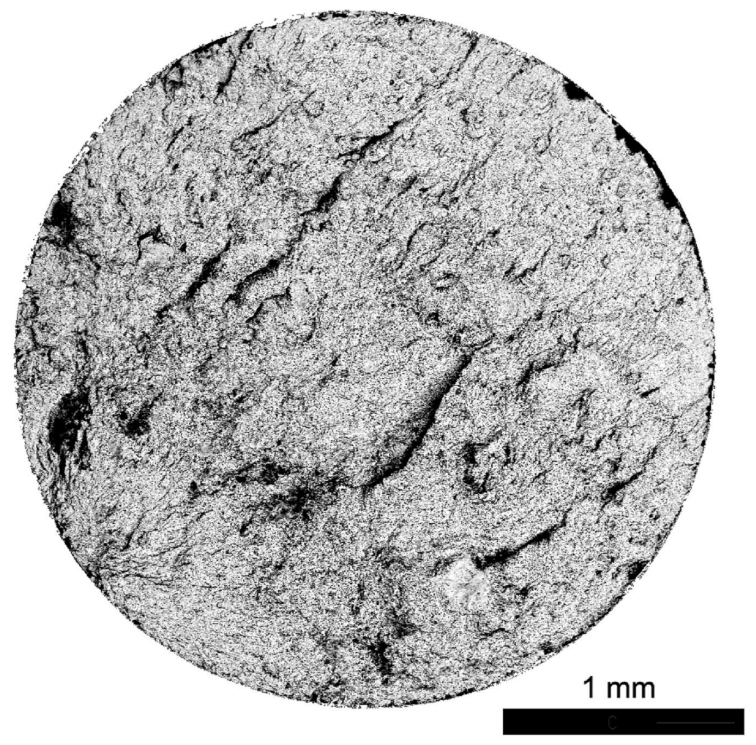

Fig. 3. Typical SEM micrograph - surface crack initiation; $\sigma_{\mathrm{a}}=475 \mathrm{MPa}, N=1.74 \times 10^{9}$.

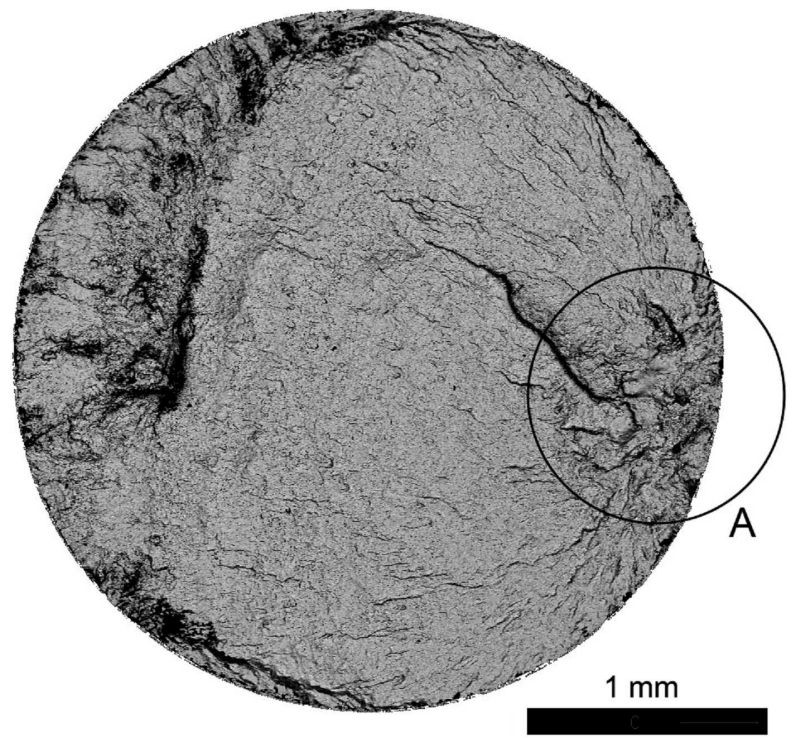

Fig. 4. Typical SEM micrograph - subsurface crack initiation; $\sigma_{\mathrm{a}}=450 \mathrm{MPa}, N=1.17 \times 10^{9}$.

that similar fatigue crack initiation and crack growth mechanisms operate both at low and high stress amplitudes and that there is no clear transition of fatigue crack initiation between HCF and VHCF region. Let us discuss the possible reasons of this experimental observation.

The internal fatigue crack initiation in structural materials is generally associated with a microstructural heterogeneity. Subsurface crack initiation with a fish-eye morphology is typical in materials with the occurrence of microstructure defects like inclusions, pores, etc. [5, 6 , $9,23]$. Wrought titanium-based alloys are characterized by extremely low content of pores and inclusions which differentiates them from commercial aluminum and magnesium alloys. 


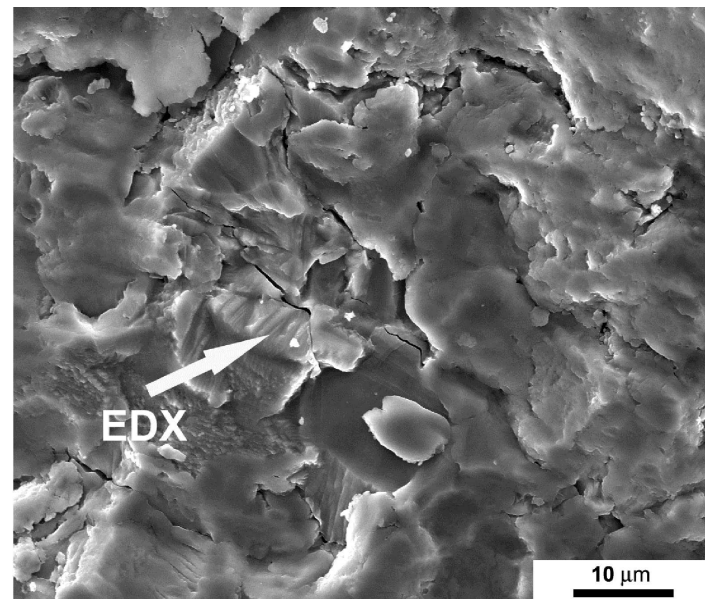

Fig. 5. Facet-like structure at the subsurface initiation site; $\sigma_{\mathrm{a}}=450 \mathrm{MPa}, N=1.17 \times 10^{9}$ and place of EDX analysis, detail of region A from Fig. 4.

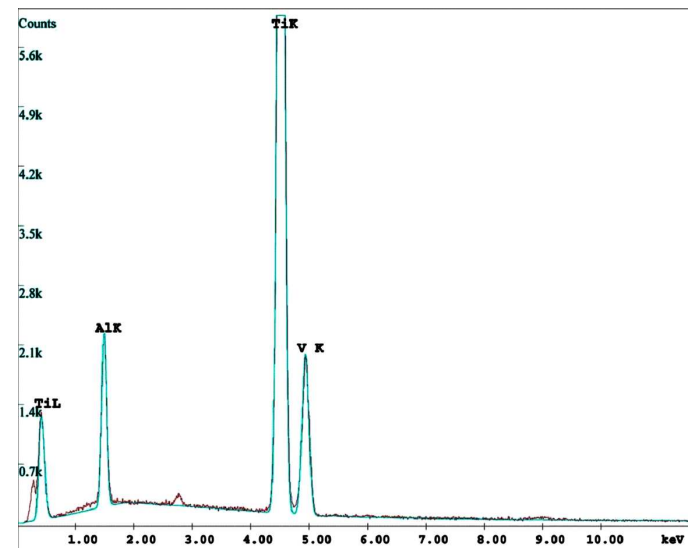

Fig. 6. Results of EDX analysis of local chemical abnormality. The content of individual elements in the Table should be taken only qualitatively.

Neither inclusions nor pores were detected at the initiation site of the investigated fracture surface. However, typical cleavage facets were observed on the surface in the crack origin in $\alpha$ grains (Fig. 5) where a local chemical abnormality was detected by EDX analysis, see Fig. 6 and the Table. Cleavage facets at crack initiation sites may be formed by three following mechanisms. Firstly, internal cracks may initiate at primary $\alpha$ grains in bimodal microstructure whose large boundaries constitute weak sites. Secondly, if a large primary $\alpha$ grain in the bimodal microstructure is situated on a plane subjected to tensile stress, the long grain boundary acts as an internal notch [10]. Thirdly, the easy crack propagation parallel to the local lamellar interfaces also causes facet formation on the fracture surface. This mechanism of internal crack initiation in the $\alpha+\beta$ titanium alloys is well known and reported in detail by many authors [10, 24, 25].

Despite the similar appearance of fracture surface at $\mathrm{HCF}$ and VHCF there are fundamental differences between fatigue mechanisms operating in these two regions. At low stress amplitudes (VHCF region), the
TABLE

The content of individual elements (qualitative determination, ZAF correction).

\begin{tabular}{c|c|c|c|c|c|c}
\hline \hline Element & [wt\%] & [at.\%] & $K$ ratio & $Z$ & $A$ & $F$ \\
\hline Al $K$ & 8.93 & 14.83 & 0.0465 & 1.0793 & 0.4817 & 1.0030 \\
Ti $K$ & 90.46 & 84.63 & 0.8905 & 0.9913 & 0.9930 & 1.0000 \\
V $K$ & 0.61 & 0.54 & 0.0060 & 0.9710 & 1.0008 & 1.0000 \\
total & 100.00 & 100.00 & & & &
\end{tabular}

macro-plasticity, which may introduce through-thickness slip or long range persistent slip bands, is inactive. Only the micro-plasticity due to microstructural heterogeneity can act as a damage mechanism [10]. In the two-phase alloy, the nature of the crack initiation site depends not only on microstructural factors, but also on the respective response of each phase to the cyclic straining [26, 27].

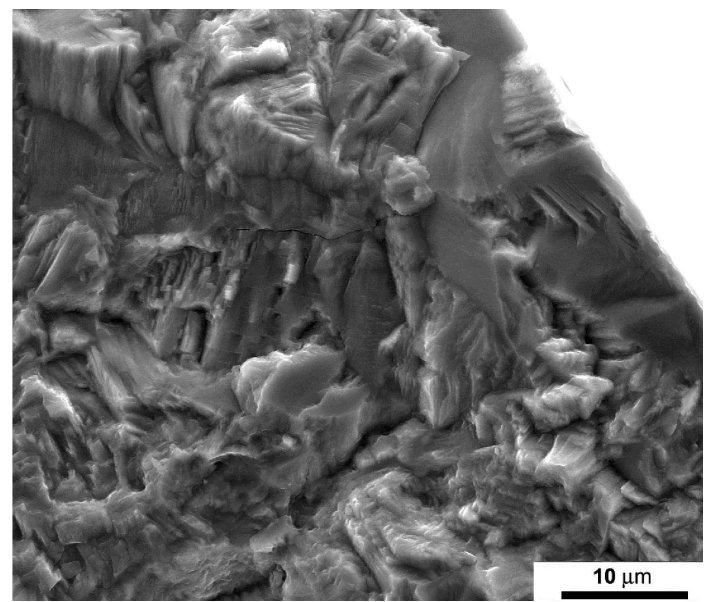

Fig. 7. Facet-like structure at the surface initiation site; $\sigma_{\mathrm{a}}=450 \mathrm{MPa}, N=6.24 \times 10^{9}$.

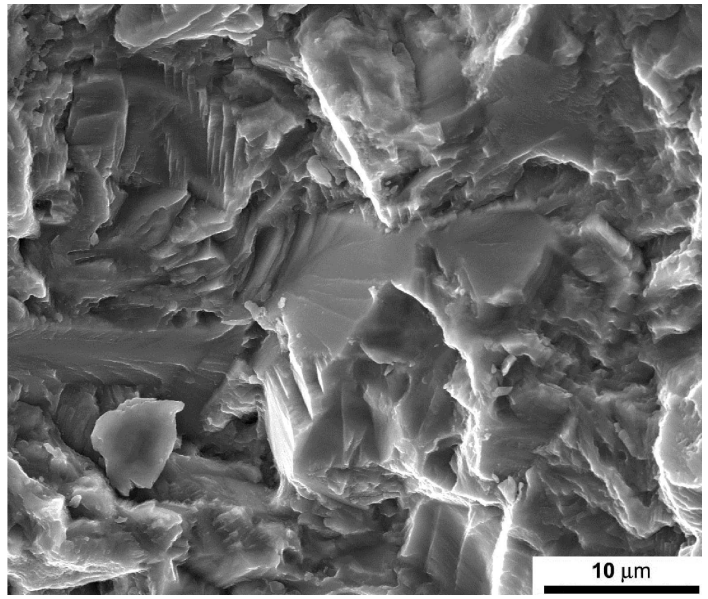

Fig. 8. Transgranular cleavage facets at the fatigue crack initiation site; $\sigma_{\mathrm{a}}=450 \mathrm{MPa}, N=6.24 \times 10^{9}$.

At high stress amplitudes (HCF region) fatigue cracks initiated at the surface of specimen due to cyclic slip deformation with the presence of stage I facets. Only 
single crack initiation occurred. Multiple crack initiation was not observed even at highest stress amplitudes. Fatigue cracks initiated in the $\alpha$ phase were observed in our previous work [28], and also reported by other authors [29, 30]. For fatigue crack initiation in VHCF region (Figs. 7,8 ) the typical transgranular cleavage facets with weakly developed featherlike features were observed.

The fatigue crack initiation at low stress amplitudes is associated with low-energy cleavage fracture that propagates along well-defined low index crystallographic planes. Low index crystallographic planes are known as cleavage planes. Therefore the specimens broken in VHCF region show clearly developed cleavage facets compared with specimens broken in HCF region. Similar results can be found in [31].

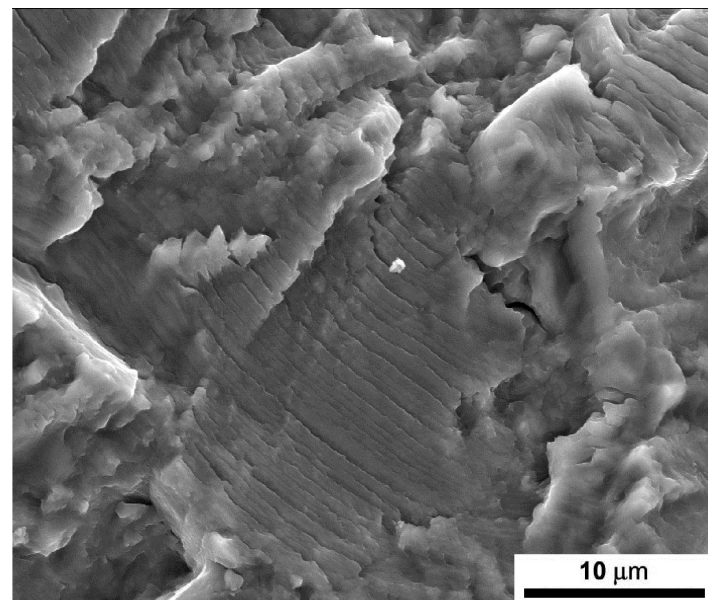

Fig. 9. Striations on the fracture surface; $\sigma_{\mathrm{a}}=$ $475 \mathrm{MPa}, N=7.46 \times 10^{7}$.

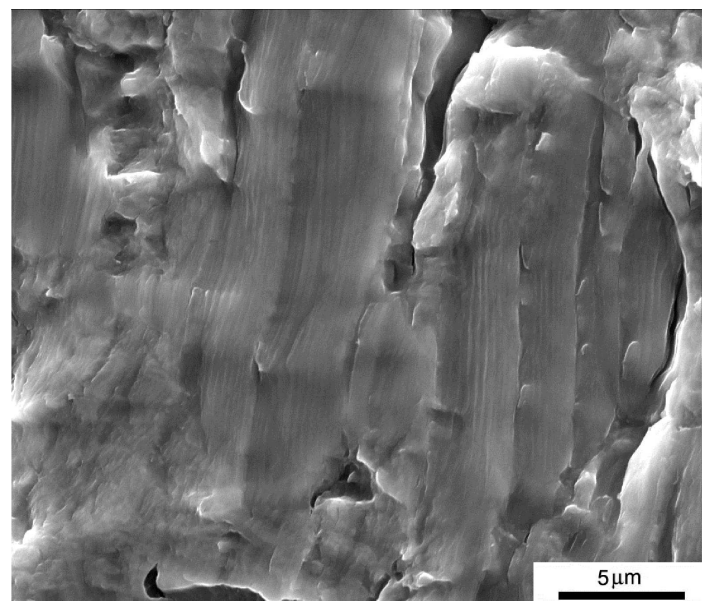

Fig. 10. Detail of fine striations; $\sigma_{\mathrm{a}}=450 \mathrm{MPa}, N=$ $5.31 \times 10^{9}$.

Transgranular fatigue fracture with radial streaks corresponding to the crack propagation can be seen in all specimens irrespective of applied stress amplitude. The fracture surfaces at high stress amplitudes have more developed secondary cracks perpendicular to the crack growth direction and striated regions with larger spacing compared to fracture surfaces at low stress amplitudes. Secondary cracks in Ti-6Al-4V alloy are known to form at the interface between acicular $\alpha$ and $\beta$ phase [32]. The fracture surfaces at low stress amplitudes, as seen in Figs. 9, 10 show very fine striations on the surface of individual facets of $\alpha$ grains at high magnifications.

\section{Conclusions}

The fatigue behaviour of $\mathrm{Ti}-6 \mathrm{Al}-4 \mathrm{~V}$ alloy in the $\mathrm{VHCF}$ region complemented by a detail fracture analysis was performed. The following conclusions may be drawn from this investigation:

- smooth S-N curve was obtained irrespective of the mode and the frequency of loading (rotating bending at $30 \mathrm{~Hz}$ vs. tension-compression at $20 \mathrm{kHz}$ ),

- the results of regression calculations show that experimental results can be properly fitted by the Palmgren function,

- two distinct regions can be distinguished in $\mathrm{S}-$ $\mathrm{N}$ curve. In low and high cycle region $\left(N<10^{7}\right)$ the curve strongly decreases with increasing number of cycles $N$, whereas in the very high cycle region $\left(N>10^{9}\right)$ the stress amplitude remains constant with increasing $N$,

- unlike other structural materials, $\mathrm{Ti}-6 \mathrm{Al}-4 \mathrm{~V}$ exhibits a distinct fatigue strength of approximately $460 \mathrm{MPa}$,

- surface crack initiation prevails in VHCF region. Subsurface cracks initiation was observed only exceptionally,

- subsurface cracks initiated from zones with no pronounced microstructural inhomogeneity (pore and/or inclusion) mainly from $\alpha$ grains.

\section{Acknowledgments}

This work was financially supported by the Grant Agency of the Czech Republic under the grant no. 1436566G. L. Trško acknowledges financial support by the European Regional Development Fund and Slovak State Budget under the project "Research Centre of the University of Žilina" with ITMS code 26220220183.

\section{References}

[1] L. Škublová, B. Hadzima, L. Borbás, M. Vitosová, Mater. Eng. - Mater. Inz. 15, 18 (2008).

[2] S. Suresh, Fatigue of Materials, University Press, Cambridge 2004.

[3] F. Nový, O. Bokůvka, P. Palček, M. Chalupová, Proc. Eng. 10, 1408 (2011). 
[4] I. Marines, X. Bin, C. Bathias, Int. J. Fatigue 25, 1101 (2003).

[5] H. Mughrabi, Int. J. Fatigue 28, 1501 (2006).

[6] F. Nový, M. Činčala, P. Kopas, O. Bokůvka, Mater. Sci. Eng. A 462, 189 (2007).

[7] C. Bathias, P.C. Paris, Gigacycle Fatigue in Mechanical Practice, Marcel Dekker, New York 2005.

[8] H. Mayer, M. Papakyriacou, B. Zettl, S. Vacic, Int. J. Fatigue 27, 1076 (2005).

[9] F. Nový, M. Janeček, V. Škorík, J. Müller, L. Wagner, Int. J. Mater. Res. 100, 288 (2009).

[10] J.H. Zhuo, Z.G. Wang, E.H. Han, Mater. Sci. Eng. A 473, 147 (2008).

[11] J. Mueller, H.J. Rack, L. Wagner, in: Ti-2007 Science and Technology, Eds. M. Niinomi, S. Akiyama, M. Ibeda, M. Hagiwara, K. Maruyama, The Japan Institute of Metals, Sendai 2007, p. 383.

[12] A. Puškár, Ultrasonics 31, 61 (1993).

[13] F. Appel, J.D.H. Paul, M. Oehring, in: Gamma Titanium Aluminide Alloys: Science and Technology, Wiley-VCH Verlag, Weinheim 2011, p. 357.

[14] Titanium and Titanium Alloys - Fundamentals and Applications, Eds. C. Leyens, M. Peters, WILEYVCH Verlag, Weinheim 2003.

[15] M. Long, H.J.Rack, Biomaterials 19, 1621 (1998).

[16] W. Weibull, Fatigue Testing and Analysis of Results, Pergamon, Oxford 1961, p. 7.

[17] J. Kohout, S. Věchet, Int. J. Fatigue 23, 175 (2001).

[18] A. Buch, Fatigue Strength Calculation, TransTech Publications, Switzerland 1988.
[19] E. Takeuchi, Y. Furuya, N. Nagashima, S. Matsuoka, Fatigue Fract. Eng. Mater. Struct. 31, 599 (2008).

[20] R.D. Pollak, A.N. Palazotto, Probabilist. Eng. Mech. 24, 236 (2009).

[21] K. Yamaguchi, T. Abe, K. Kobayashi, E. Takeuchi, H. Hirukawa, Y. Maeda, N. Nagashima, M. Hayakawa, Y. Furuya, M. Shimodaira, K. Miyahara, Sci. Technol. Adv. Mater. 8, 545 (2007).

[22] R.J. Morrissey, T. Nicholas, Int. J. Fatigue 27, 1608 (2005).

[23] Y. Furuya, S. Matsuoka, T. Abe, K. Yamaguchi, Scr. Mater. 46, 157 (2002).

[24] I. Bantounas, D. Dye, T.C. Lindley, Acta Mater. 57, 3584 (2009).

[25] M.R. Bache, Int. J. Fatigue 21, S105 (1999).

[26] J. Stolarz, J. Foc, Mater. Sci. Eng. A 319-321, 501 (2001).

[27] G. Chai, Int. J. Fatigue 28, 1611 (2006).

[28] M. Janeček, F. Nový, J. Stráský, P. Harcuba, L. Wagner, J. Mech. Behav. Biomed. Mater. 4, 417 (2011).

[29] R.K. Nalla, B.L. Boyce, J.P. Campel, J.O. Peters, J.O. Ritchie, Metall. Mater. Trans. 33A, 899 (2002).

[30] K. Tokaji, Scr. Mater. 54, 2143 (2006).

[31] S. Mall, T. Nicholas, Tae-Won Park, Int. J. Fatigue 25, 1109 (2003).

[32] M. Peters, A. Gysler, G. Luetjering, in: Titanium '80 Science and Technology, Eds. H. Kimura, O. Izumi, Metallurgical Society of AIME, Warrendale 1980, p. 1777 . 